\title{
Long-term results of a study using individualized planning target volumes for hypofractionated intensity-modulated radiotherapy boost for prostate cancer
}

William Chu ${ }^{1,2}$, D Andrew Loblaw ${ }^{1,2}$, Kelvin Chan ${ }^{3}$, Gerard Morton ${ }^{1,2}$, Richard Choo ${ }^{4}$, Ewa Szumacher ${ }^{1,2}$, Cyril Danjoux ${ }^{1,2}$, Jean-Philippe Pignol ${ }^{1,2}$ and Patrick Cheung ${ }^{1,2^{*}}$

\begin{abstract}
Background: This is the final report of a prospective phase I study which evaluated the feasibility, toxicities, and biochemical control in prostate cancer patients treated with a hypofractionated boost utilizing a fiducial marker-based daily image guidance strategy and small patient-specific PTV margins.

Methods: Low- and intermediate-risk prostate cancer patients underwent transperineal ultrasound-guided implantation of three gold fiducial markers and were treated with three-dimensional conformal radiotherapy to 42 Gy (2 Gy/day). During the first nine fractions of treatment, pre- and post-treatment electronic portal imaging was performed to calculate intrafraction prostate motion. Patient-specific PTV margins were derived and a $30 \mathrm{~Gy}$ (3 Gy/day) intensity modulated radiotherapy boost was delivered (Total dose $=72 \mathrm{~Gy}$ in 31 fractions; EQD2 = $81 \mathrm{~Gy}, \mathrm{\alpha} / \beta=1.4$ ).

Results: Thirty-three patients completed treatment and were followed for a median of 7.2 years (range, $1.2-9.5$ ). Seven patients (21\%) developed Radiation Therapy Oncology Group (RTOG) late grade 2 Gl toxicity and 1 patient (3\%) developed late grade $2 \mathrm{GU}$ toxicity. No patients developed late grade $3 \mathrm{Gl}$ or GU toxicity. To date, nine patients developed PSA relapse according to the Phoenix criteria. The actuarial five, seven and nine year biochemical control (BC) rates were 87\% (95\% confidence interval: 69-95), 77\% (95\% confidence interval: 56-89) and 66\% (95\% confidence interval: 42-82).
\end{abstract}

Conclusions: Our study demonstrates that the use of prostate fiducial markers in combination with a daily online image guidance protocol permits reduced, patient-specific PTV margins in a hypofractionated treatment scheme. This treatment planning and delivery strategy was well tolerated in the intermediate time frame. The use of very small PTV margins did not result in excessive failures when compared to other radiation regimens of similar radiobiological intensity.

Keywords: Biochemical outcomes, Hypofractionation, Image-guided radiotherapy, Intensity modulated radiotherapy, Prostate cancer, Toxicity

\footnotetext{
* Correspondence: Patrick.Cheung@sunnybrook.ca

'Department of Radiation Oncology, Odette Cancer Centre, Sunnybrook

Health Sciences Centre, 2075 Bayview Ave., Toronto, ON M4N 3 M5, Canada

${ }^{2}$ Department of Radiation Oncology, University of Toronto, Toronto, ON,

Canada

Full list of author information is available at the end of the article
} 


\section{Background}

Radiotherapy is a widely accepted treatment option for localized prostate cancer. Technological advances in imaging, treatment planning and delivery techniques have transformed radiotherapy. Randomized trials with dose-escalated radiotherapy (74 - 80 Gy) demonstrate an improvement in biochemical control compared to conventional treatment regimens (64 - 70 Gy) [1-9]. However, dose escalation using $3 \mathrm{D}-\mathrm{CRT}$ is associated with an increase in late rectal toxicity [10].

Investigators have reported a $\alpha / \beta$ ratio as low as 1.4 for prostate tumours, which is lower than the surrounding rectum and bladder [11-16]. As such, there has been rising interest in using hypofractionated radiotherapy (higher doses per fraction with fewer fractions) to capitalize on the sensitivity of prostate tumours to high fraction sizes while maintaining similar or lowering rates of late normal tissue toxicity. Furthermore, there is the potential for lower costs and improved patient convenience with a shorter course of treatment [17].

Inter- and intrafraction prostate motion is not negligible [18-20]. The essential elements to safely deliver hypofractionated radiotherapy include the utilization of a daily image-guidance strategy and quantifying the geometric uncertainties associated with the treatment technique to derive the optimal planning target volume (PTV) margins to maximize tumour control while limiting late normal tissue toxicity. For this prospective phase I study, we previously presented the feasibility of a fiducial marker-based daily image guidance strategy to deliver a hypofractionated boost to low and intermediate risk prostate cancer patients. We quantified intrafraction prostate motion, derived patient-specific PTV margins and presented the associated acute toxicities of this treatment technique [21]. In this report, we present the late toxicity and efficacy data.

\section{Methods and materials Eligibility criteria}

From 2002 to 2003, patients with biopsy proven lowand intermediate-risk adenocarcinoma of the prostate were eligible for this study [22]. These included patients with T1-2, Gleason score $\leq 7$, and PSA $\leq 20 \mathrm{ng} / \mathrm{mL}$ prostate cancer [23]. Patients with evidence of nodal or distant metastases were ineligible. Written consent was obtained from all patients. This project was approved by the Research Ethics Board of the Sunnybrook Health Sciences Centre.

\section{Conventional 3D-CRT planning and treatment delivery}

Patients underwent transperineal ultrasound-guided implantation of three gold fiducial markers into the prostate, CT simulation in the supine position with a custom vacuum lock bag for immobilization, and digital fluoroscopic imaging of respiratory-induced prostate motion as previously described [21].

The clinical target volume (CTV) consisted of the prostate and the lowest portion of the seminal vesicles directly posterior to the prostate. There was no attempt to include the seminal vesicles above the most superior slice of the prostate. For the first phase of treatment, a 10-mm PTV margin was added to the CTV in all directions to account intra- and interfraction prostate motion. The rectum was contoured as a single solid organ from the bottom of the ischium to the sigmoid flexure. The bladder was contoured as a single solid organ. A conventional four-field 3D-CRT technique was used to deliver a dose of 42 Gy in 21 fractions (2 Gy/day) to the isocenter without daily image guidance. AP and right lateral digitally reconstructed radiographs were developed to document the location of the fiducial markers relative to the treatment field. During the first nine fractions of treatment, pre- and post-treatment electronic portal imaging was performed to calculate intrafraction prostate motion [21].

\section{Patient-specific PTV margins and intensity modulated radiation (IMRT) boost phase}

Using the intrafraction prostate motion data generated from the first phase of treatment, patient-specific PTV margins were generated in the anterior-posterior (AP), superior-inferior (SI) and medial-lateral (ML) directions for the IMRT boost phase [21].

An optimized segmented seven- to nine-field IMRT plan was developed to deliver a dose of $30 \mathrm{~Gy}$ in 10 fractions (3 Gy/day) to the patient-specific PTV using inverse planning software (Nomos Corvus). Normal tissue constraints for the IMRT plan were designed to limit the dose to $30 \%$ of the rectum and bladder to $60 \mathrm{~Gy}$ or less (in equivalent 2-Gy fractions, assuming an $\alpha / \beta$ value of 2 ) for the two treatment phases combined. From the two phases combined, the prostate received a total dose of 72 Gy in 31 fractions; an equivalent of 81 Gy in 2 Gy fractions $(\alpha / \beta=1.4)$ [13]. These calculations were made using the linear quadratic formula.

Daily image-guidance during the boost phase was achieved by electronic portal imaging in the AP and right lateral direction, and matching the positions of the implanted fiducial markers relative to their initial reference positions on the planning DRR through couch shifts. Only displacements $>2 \mathrm{~mm}$ were corrected since our own in-house measurements determined the accuracy of the online targeting and correction process to be no less than $2 \mathrm{~mm}$. The IMRT plan incorporated the dose delivered to the prostate and normal tissues from the daily pretreatment imaging. 


\section{Toxicity assessment}

Time zero was defined as the start of radiotherapy. Late GI and GU toxicity were assessed using the RTOG/ EORTC Late Radiation Morbidity Scheme [24] at 6, 12, 18 , and 24 months.

\section{Biochemical control}

For follow-up, patients had a digital rectal examination and serum PSA performed at 3 and 6 months, and then every 6 months for the first 5 years. Thereafter, follow-up was at the discretion of the attending physician. Biochemical failure was defined using the Phoenix definition (nadir $+2 \mathrm{ng} / \mathrm{ml}$ ) [25].

\section{Sample size and statistical analysis}

At the inception of our study, we estimated the incidence of late grade 2 or greater rectal toxicity between $3 \%$ and $14 \%$ with our combined 3D-CRT/IMRT treatment technique [26]. Our planned accrual was 30 patients. Time to PSA relapse was defined as the period between the start of radiation treatment and PSA relapse. Patients free from PSA relapse at the end of the study period or by the time they withdrew from the study were censored. The Kaplan-Meier method was used to estimate the PSA relapse-free rate [27]. Statistical analysis was performed in SAS 9.3 (Cary, NC, USA).

\section{Results}

At the time of analysis 33 patients had completed treatment and been followed for a median of 7.2 years (range, 1.2 - 9.5). The majority of patients had intermediaterisk disease $(79 \%)$ and the remainder had low-risk disease $(21 \%)$ according to the Canadian consensus on prostate cancer risk stratification (ref). Patient characteristics are summarized in Table 1.

The average PTV margin used during the IMRT hypofractionated boost was $4 \mathrm{~mm}$ in the AP direction (range, 2-8 $\mathrm{mm}$ ), $3 \mathrm{~mm}$ in SI direction (range, $2-7 \mathrm{~mm}$ ), and $3 \mathrm{~mm}$ in the RL direction (range, $2-5 \mathrm{~mm}$ ) [21].

Seven patients (21\%) developed late grade 2 GI toxicity and 1 patient (3\%) developed late grade 2 GU toxicity. No patients developed late grade 3 GI or GU toxicity after two years of follow-up.

To date, nine patients developed PSA relapse according to the Phoenix criteria. The actuarial five, seven and nine year biochemical control (BC) rates were 87\% (95\% confidence interval: 69-95), 77\% (95\% confidence interval: $56-89)$ and $66 \%$ (95\% confidence interval: $42-82$ ) (Figure 1).

\section{Discussion}

We previously showed that the magnitude of intrafraction prostate motion was small (AP $0.72 \pm 1.80 \mathrm{~mm}$, SI $0.45 \pm 1.27 \mathrm{~mm}$ and ML $0.14 \pm 0.92 \mathrm{~mm})$, and derived
Table 1 Patient characteristics $(\mathbf{n}=\mathbf{3 3}$ )

\begin{tabular}{ll}
\hline Median age & $\begin{array}{l}\mathbf{6 9} \text { years } \\
\text { (Range, 53-80) }\end{array}$ \\
\hline Clinical stage & $20(60.6 \%)$ \\
T1c & $13(39.4 \%)$ \\
T2a & \\
Gleason score & $12(36.4 \%)$ \\
6 & $21(63.6 \%)$ \\
7 & \\
Pretreatment PSA (ng/ml) & $23(69.7 \%)$ \\
$\leq 10$ & $10(30.3 \%)$ \\
$10-20$ & \\
Risk stratification & $7(21.2 \%)$ \\
Low & $26(78.8 \%)$ \\
Intermediate & \\
\hline
\end{tabular}

average PTV margins of $4 \mathrm{~mm}$ (range 2-8 mm) AP, $3 \mathrm{~mm}$ (range 2-7 $\mathrm{mm}$ ) SI and $3 \mathrm{~mm}$ (range 2-5 mm) ML [21]. Since our initial report, additional analyses of prostate fiducial markers with electronic portal images corroborate our findings [28-30]. Kotte et al. [28] showed that margins of at least $2 \mathrm{~mm}$ account for intrafraction prostate motion, and Middleton et al. [29] derived PTV margins (AP $3.9 \mathrm{~mm}$, SI $3.2 \mathrm{~mm}$ and $\mathrm{ML}$ $4.3 \mathrm{~mm}$ ) that were comparable to ours.

The goal of utilizing a daily-image guidance strategy and reducing the PTV margin is to realize a clinically meaningful difference in treatment toxicity. In the randomized trials of dose escalation the PTV margins used across the studies were heterogeneous, ranging from 5$15 \mathrm{~mm}$. While these studies demonstrated a benefit in biochemical control, there was an increase in late grade 2 or greater GI toxicity (odds ratio of 1.58 ; 99\% CI 1.242; p < 0.0001) [31]. In Tables 2 and 3, the PTV margins utilized and the reported late toxicities in the randomized trials of dose escalation [1-9], and contemporary mild hypofractionation [32-36], are summarized alongside the results of the current study for illustrative purposes. Our study was limited by a small sample size and only two years of toxicity follow-up. The variability in the reported toxicities across studies is likely due to differences in the PTV margins, treatment techniques, and dose and fractionation schedules.

Since Brenner and Hall first reported that prostate cancer may have a low $\alpha / \beta$ ratio [14], there has been growing interest to use hypofractionated treatment regimens to capitalize on the therapeutic ratio that may exist between the sensitivity of prostate cancer to higher doses of radiation per treatment fraction and reduced normal tissue toxicity. The promise of hypofractionation lies in the potential for improved tumour control and increased patient 


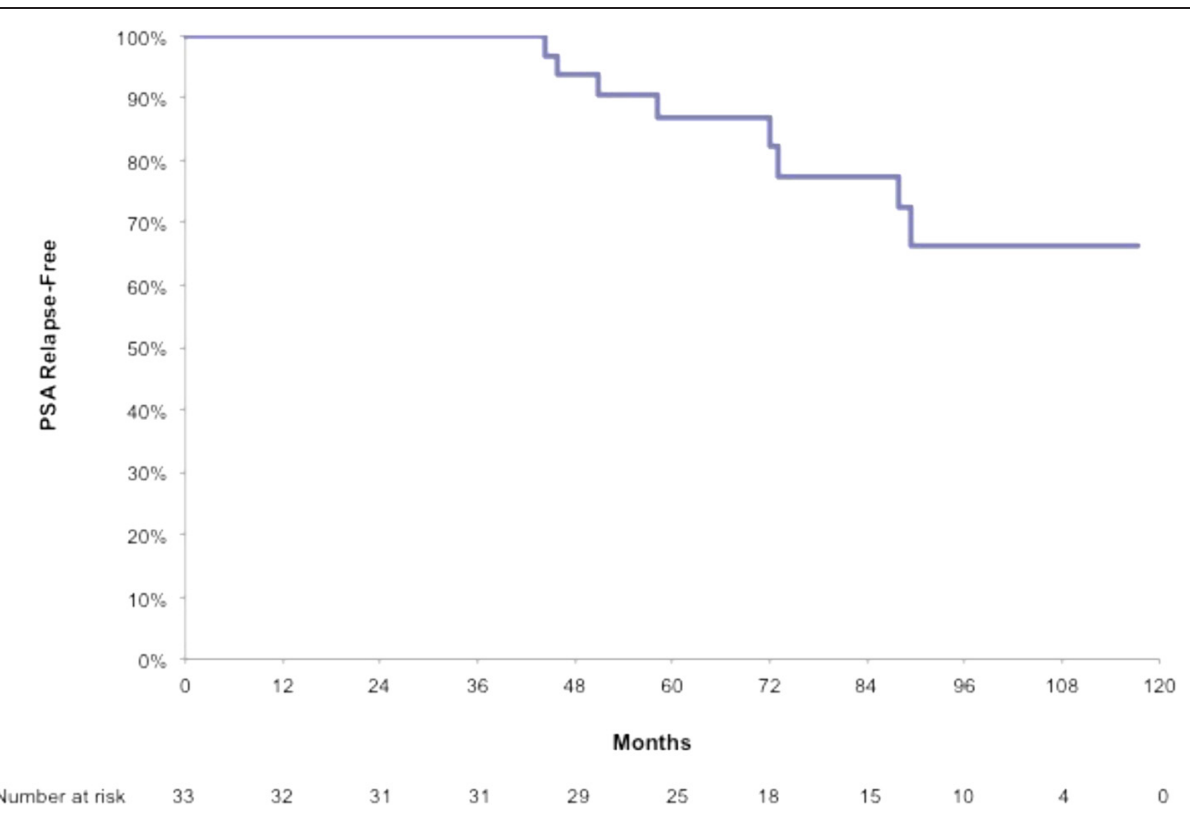

Figure 1 Actuarial analysis of biochemical control.

convenience with a shorter overall treatment time and lower costs compared to a standard course of doseescalated treatment. To date, data from four contemporary randomized trials comparing hypofractionated to doseescalated radiotherapy do not demonstrate increased biochemical control with higher biologic equivalent doses to the prostate and equivalent late toxicities [34,36]; or the same biochemical control and less late toxicity with isoeffective doses delivered to the prostate as hypothesized [32,33,37-39] (Table 3).

Table 2 Summary of randomized trials of dose-escalated external beam radiotherapy

\begin{tabular}{|c|c|c|c|c|c|}
\hline Study & MDACC (1) & Dutch $(2,3,4)$ & PROG $(5,6)$ & MRC RT01 $(7,8)$ & GETUG 06 (9) \\
\hline Dose (technique) & $\begin{array}{l}78 \text { Gy ( } 4 \text {-fld box + 3D-CRT) } \\
\text { vs } 70 \text { Gy ( } 4 \text {-fld box) }\end{array}$ & $\begin{array}{l}78 \text { Gy (4-fld box + 3D-CRT/ } \\
\text { IMRT) vs } 68 \text { Gy (4-fld box) }\end{array}$ & $\begin{array}{l}79.2 \text { GyE (4-fld box + proton boost) } \\
\text { vs } 70.2 \text { Gy ( } 4 \text {-fld box + proton boost) }\end{array}$ & $\begin{array}{l}74 \text { Gy (3D-CRT) vs } \\
64 \text { Gy (3D-CRT) }\end{array}$ & $\begin{array}{l}80 \text { Gy (3D-CRT) vs } \\
70 \text { Gy (3D-CRT) }\end{array}$ \\
\hline Median F/U (yrs) & 9 & 5.8 & 8.9 & 5.2 & 5.1 \\
\hline *PTV margins (mm) & $\begin{array}{l}\text { Ant/Inf } 12.5-15 \\
\text { Post/Sup } 7.5-10\end{array}$ & $\begin{array}{l}10 \text { to } 68 \text { Gy } 5 \text { for } \\
10 \text { Gy boost } 0 \text { Post }\end{array}$ & $\begin{array}{l}10 \text { to } 50.4 \text { Gy } 5 \text { for } \\
28.8 \text { GyE (proton boost) }\end{array}$ & $5-10$ & $\begin{array}{l}\text { Ant/Sup/Inf/RL } \\
10 \text { Post } 5\end{array}$ \\
\hline *Late toxicity (\%) & RTOG & RTOG & RTOG & RTOG & RTOG \\
\hline \multicolumn{6}{|l|}{$\geq$ Grade 2} \\
\hline Gl & 26 & 35 & 24 & 33 & 20 \\
\hline GU & 13 & 40 & 29 & 11 & 18 \\
\hline \multicolumn{6}{|l|}{ Grade 3} \\
\hline Gl & 7 & 5 & 1 & 4 & 6 \\
\hline GU & 4 & 7 & 2 & 0 & 2 \\
\hline \multicolumn{6}{|l|}{ Grade 4} \\
\hline Gl & none & 1 patient & none & none & none \\
\hline GU & none & none & none & none & 1 patient \\
\hline \multirow{4}{*}{$\begin{array}{l}\text { Biochemical } \\
\text { control (\%) }\end{array}$} & Phoenix & ASTRO & ASTRO & ASTRO & Phoenix \\
\hline & $5 \mathrm{yr}-85$ vs 78 & $7 y r-54$ vs 47 & $5 \mathrm{yr}-80$ vs 61 & $5 \mathrm{yr}-71$ vs 59 & $5 y r-76$ vs 68 \\
\hline & $8 \mathrm{yr}-78$ vs 59 & Phoenix & $10 y r-83$ vs 68 & & \\
\hline & $10 \mathrm{yr}-73$ vs 50 & $7 \mathrm{yr}-54$ vs 45 & & & \\
\hline
\end{tabular}


Table 3 Summary of randomized trials of mild hypofractionated radiotherapy

\begin{tabular}{|c|c|c|c|c|c|}
\hline Study & MDACC (33) & $\operatorname{FCCC}(34,35)$ & RENCI $(31,36,37)$ & UK CHHiP (32) & Current study \\
\hline $\begin{array}{l}\text { Dose/fractions } \\
(\mathrm{EQD} 2 \mathrm{a} / \beta=1.4)\end{array}$ & $\begin{array}{l}72 \mathrm{~Gy} / 30 \text { (80Gy) vs } \\
75.6 \mathrm{~Gy} / 42 \text { (71 Gy) }\end{array}$ & $\begin{array}{l}70.2 \mathrm{~Gy} / 26(84 \mathrm{~Gy}) \\
\text { vs } 76 \mathrm{~Gy} / 38\end{array}$ & $\begin{array}{l}62 \mathrm{~Gy} / 20(82 \mathrm{~Gy}) \\
\text { vs } 80 \mathrm{~Gy} / 40\end{array}$ & $\begin{array}{l}60 \mathrm{~Gy} / 20 \text { (77.6 Gy); } 57 \mathrm{~Gy} / 19 \\
\text { (73.8 Gy) vs } 74 \mathrm{~Gy} / 37\end{array}$ & $\begin{array}{l}42 \text { Gy/21 plus } \\
30 \text { Gy/10 (81 Gy) }\end{array}$ \\
\hline Median F/U (yrs) & 4.8 & 5 & 2.9 & 4.2 & 7.2 \\
\hline \multirow[t]{9}{*}{ *PTV margins (mm) } & Not reported & Ant/Sup/Inf/RL7 Post 3 & 10 & PTV1 (80\%) & Phase 1 - 10 \\
\hline & & & & Ant/Sup/Inf/RL 10 & Phase 2 \\
\hline & & & & Post 10 & AP 4 \\
\hline & & & & PTV2 (96\%) & SI 3 \\
\hline & & & & Ant/Sup/Inf/RL 10 & RL 3 \\
\hline & & & & Post 5 & \\
\hline & & & & PTV3 (100\%) & \\
\hline & & & & Ant/Sup/Inf/RL 5 & \\
\hline & & & & Post 0 & \\
\hline *LateToxicity (\%) & RTOG & NR & RTOG & RTOG & RTOG \\
\hline \multicolumn{6}{|l|}{$\geq$ Grade 2} \\
\hline Gl & 11 & 6 & 17 & 3.6 (60 Gy); 1.4 (57 Gy) & 21 \\
\hline GU & 19 & 14 & 14 & 2.2 (60 Gy); 0 (57 Gy) & 3 \\
\hline \multicolumn{6}{|l|}{ Grade 3} \\
\hline $\mathrm{Gl}$ & 3 & $N R$ & 1 patient & none & none \\
\hline GU & 0 & NR & none & none & none \\
\hline \multicolumn{6}{|l|}{ Grade 4} \\
\hline $\mathrm{Gl}$ & none & NR & none & none & none \\
\hline GU & none & NR & none & none & none \\
\hline \multirow[t]{4}{*}{ Biochemical control (\%) } & Phoenix & Phoenix & Phoenix & & Phoenix \\
\hline & $5 y r-97$ vs 94 & 5 yr -86 vs 86 & $5 \mathrm{yr}-85$ vs 79 & NR & $5 y r-87$ \\
\hline & ASTRO & & & & $7 y r-77$ \\
\hline & $5 y r-96$ vs 92 & & & & $9 y r-66$ \\
\hline
\end{tabular}

MDACC - MD Anderson Cancer Centre; FCCC - Fox Chase Cancer Center; RENCI - Regina Elena National Cancer Institute; UK CHHiP - United Kingdom Conventional or Hypofractionated High-dose Intensity Modulated Radiotherapy in Prostate Cancer. *Hypofractionated arm only; NR - not reported.

Based on a $\alpha / \beta$ ratio of 1.4 [13], we delivered an equivalent dose of 81 Gy in 2 Gy fractions. Our pilot study was small, however, it was reassuring to observe that our BC rate was similar to the MD Anderson (8year Phoenix 78\%) [1]; and higher than the UK (5-year ASTRO 71\%) [7,8], French (5-year Phoenix 76\%) [9] and Dutch (7-year Phoenix 56\%) [3,4] dose-escalation trials. In comparison to the hypofractionated treatment arms of the mild hypofractionation trials (Table 3), our BC rate was also similar to the rates reported by Pollack et al. [36] (5-year Phoenix 86\%) and Arcangeli et al. $[32,37,38]$ (5-year Phoenix 85\%), and lower than the rate reported by Kuban et al. [34] (5-year Phoenix 96\%). While these comparisons look favourable, we recognize the wide confidence intervals in our $\mathrm{BC}$ rate due to the small sample size. Furthermore, we have not reached a plateau in our biochemical control curve like those seen with brachytherapy where higher biological doses are given $[40,41]$. This suggests that further biological doseescalation is warranted. Our group and others have explored more extreme hypofractionation protocols [42-46]. Recent reports of 135 low- and intermediate-risk patients treated with stereotactic body radiotherapy (SBRT; median follow-up 60 months) showed a 5-year bDFS of 99\% for low-risk patients and 93\% for intermediate-risk patients. Grade 3 or higher toxicities are reported in approximately $1 \%$ of patients with 35-40 Gy delivered with 5 -fraction SBRT $[43,47]$. Thus, the benefits of hypofractionation are being realized with doses of 7-8 Gy per fraction.

\section{Conclusions}

Our study demonstrates that the use of prostate fiducial markers in combination with a daily online image guidance protocol permits reduced, patient-specific PTV margins in a hypofractionated treatment scheme. This 
treatment planning and delivery strategy was well tolerated in the intermediate time frame. The use of very small PTV margins did not result in excessive failures when compared to other radiation regimens of similar radiobiological intensity. We have applied this strategy to our studies of extreme hypofractionation.

\section{Abbreviations}

3D-CRT: Three-dimensional conformal radiotherapy; RTOG: Radiation Therapy Oncology Group; PTV: Planning target volume; CTV: Clinical target volume; IMRT: Intensity modulated radiotherapy; AP: Anterior-posterior; SI: Superior-inferior; ML: Medial-lateral.

\section{Competing interests}

The authors declare that they have no competing interests.

\section{Authors' contributions}

WC analyzed and interpreted the data, and drafted and critically reviewed the manuscript. AL conceived the study, acquired, analyzed and interpreted the data, and critically reviewed the manuscript. KC completed the statistical analysis and critically reviewed the manuscript. GM acquired the data and critically reviewed the manuscript. RC acquired the data and critically reviewed the manuscript. ES acquired the data and critically reviewed the manuscript. CD acquired the data and critically reviewed the manuscript. J-P $\mathrm{P}$ acquired the data and critically reviewed the manuscript. PC conceived the study, acquired, analyzed and interpreted the data, and critically reviewed the manuscript. All authors read and approved the final manuscript.

\section{Acknowledgements}

We gratefully acknowledge Andrea Deabreu for her hard work and dedication in the collection and maintenance of patient data, and Alex Mamedov for the creation and maintenance of the study database.

\section{Author details}

'Department of Radiation Oncology, Odette Cancer Centre, Sunnybrook Health Sciences Centre, 2075 Bayview Ave., Toronto, ON M4N 3 M5, Canada. ${ }^{2}$ Department of Radiation Oncology, University of Toronto, Toronto, ON Canada. ${ }^{3}$ Department of Medical Oncology, Odette Cancer Centre, Sunnybrook Health Sciences Centre, Toronto, ON, Canada. ${ }^{4}$ Department of Radiation Oncology, Mayo Clinic, Rochester, MN, USA.

Received: 13 May 2014 Accepted: 2 April 2015

Published online: 18 April 2015

\section{References}

1. Kuban DA, Tucker SL, Dong L, Starkschall G, Huang EH, Cheung MR, et al. Long-term results of the M. D. Anderson randomized dose-escalation trial for prostate cancer. Int J Radiat Oncol Biol Phys. 2008;70(1):67-74.

2. Peeters ST, Heemsbergen WD, van Putten WL, Slot A, Tabak H, Mens JW, et al. Acute and late complications after radiotherapy for prostate cancer results of a multicenter randomized trial comparing 68 Gy to 78 Gy. Int J Radiat Oncol Biol Phys. 2005;61(4):1019-34.

3. Peeters ST, Heemsbergen WD, Koper PC, van Putten WL, Slot A, Dielwart $M F$, et al. Dose-response in radiotherapy for localized prostate cancer: results of the Dutch multicenter randomized phase III trial comparing 68 Gy of radiotherapy with 78 Gy. J Clin Oncol. 2006;24(13):1990-6.

4. Al-Mamgani A, van Putten WL, Heemsbergen WD, van Leenders GJ, Slot A, Dielwart MF, et al. Update of Dutch multicenter dose-escalation trial of radiotherapy for localized prostate cancer. Int J Radiat Oncol Biol Phys. 2008;72(4):980-8

5. Zietman AL, DeSilvio ML, Slater JD, Rossi Jr CJ, Miller DW, Adams JA, et al. Comparison of conventional-dose vs high-dose conformal radiation therapy in clinically localized adenocarcinoma of the prostate: a randomized controlled trial. JAMA. 2005;294(10):1233-9.

6. Zietman AL, Bae K, Slater JD, Shipley WU, Efstathiou JA, Coen JJ, et al. Randomized trial comparing conventional-dose with high-dose conformal radiation therapy in early-stage adenocarcinoma of the prostate: long-term results from proton radiation oncology group/american college of radiology 95-09. J Clin Oncol. 2010;28(7):1106-11.
7. Dearnaley DP, Sydes MR, Graham JD, Aird EG, Bottomley D, Cowan RA, et al. Escalated-dose versus standard-dose conformal radiotherapy in prostate cancer: first results from the MRC RT01 randomised controlled trial. Lancet Oncol. 2007;8(6):475-87.

8. Syndikus I, Morgan RC, Sydes MR, Graham JD, Dearnaley DP. Late gastrointestinal toxicity after dose-escalated conformal radiotherapy for early prostate cancer: results from the UK Medical Research Council RT01 trial (ISRCTN47772397). Int J Radiat Oncol Biol Phys. 2010;77(3):773-83.

9. Beckendorf V, Guerif S, Le Prise E, Cosset JM, Bougnoux A, Chauvet B, et al. 70 Gy versus 80 Gy in localized prostate cancer: 5-year results of GETUG 06 randomized trial. Int J Radiat Oncol Biol Phys. 2011;80(4):1056-63.

10. Viani GA, Stefano EJ, Afonso SL. Higher-than-conventional radiation doses in localized prostate cancer treatment: a meta-analysis of randomized, controlled trials. Int J Radiat Oncol Biol Phys. 2009;74(5):1405-18.

11. Brenner DJ, Martinez AA, Edmundson GK, Mitchell C, Thames HD, Armour EP. Direct evidence that prostate tumors show high sensitivity to fractionation (low alpha/beta ratio), similar to late-responding normal tissue. Int J Radiat Oncol Biol Phys. 2002;52(1):6-13.

12. Fowler J, Chappell R, Ritter M. Is alpha/beta for prostate tumors really low? Int J Radiat Oncol Biol Phys. 2001;50(4):1021-31.

13. Miralbell R, Roberts SA, Zubizarreta E, Hendry JH. Dose-fractionation sensitivity of prostate cancer deduced from radiotherapy outcomes of 5,969 patients in seven international institutional datasets: alpha/beta $=1.4(0.9-2.2)$ Gy. Int J Radiat Oncol Biol Phys. 2012;82(1):e17-24.

14. Brenner DJ, Hall EJ. Fractionation and protraction for radiotherapy of prostate carcinoma. Int J Radiat Oncol Biol Phys. 1999;43(5):1095-101.

15. Daşu A. Is the alpha/beta value for prostate tumours low enough to be safely used in clinical trials? Clin Oncol (R Coll Radiol). 2007;19(5):289-301.

16. Thames HD, Bentzen SM, Turesson I, Overgaard M, Van den Bogaert W Time-dose factors in radiotherapy: a review of the human data. Radiol Oncol. 1990;19(3):219-35.

17. Sethukavalan P, Cheung P, Tang Cl, Quon H, Morton G, Nam R, et al. Patient costs associated with external beam radiotherapy treatment for localized prostate cancer: the benefits of hypofractionated over conventionally fractionated radiotherapy. Can J Urol. 2012;19(2):6165-9.

18. Aubry JF, Beaulieu L, Girouard LM, Aubin S, Tremblay D, Laverdière J, et al. Measurements of intrafraction motion and interfraction and intrafraction rotation of prostate by three-dimensional analysis of daily portal imaging with radiopaque markers. Int J Radiat Oncol Biol Phys. 2004;60(1):30-9.

19. Ghilezan MJ, Jaffray DA, Siewerdsen JH, Van Herk M, Shetty A, Sharpe MB, et al. Prostate gland motion assessed with cine-magnetic resonance imaging (cine-MRI). Int J Radiat Oncol Biol Phys. 2005;62(2):406-17.

20. Kupelian P, Willoughby T, Mahadevan A, Djemil T, Weinstein G, Jani S, et al. Multi-institutional clinical experience with the Calypso System in localization and continuous, real-time monitoring of the prostate gland during external radiotherapy. Int J Radiat Oncol Biol Phys. 2007;67(4):1088-98.

21. Cheung P, Sixel K, Morton G, Loblaw DA, Tirona R, Pang G, et al. Individualized planning target volumes for intrafraction motion during hypofractionated intensity-modulated radiotherapy boost for prostate cancer. Int J Radiat Oncol Biol Phys. 2005;62(2):418-25.

22. Lukka H, Warde P, Pickles T, Morton G, Brundage M, Souhami L. Controversies in prostate cancer radiotherapy: consensus development. Can J Urol. 2001;8(4):1314-22.

23. Sobin LH, Fleming ID. TNM Classification of Malignant Tumors, fifth edition (1997). Union Internationale Contre le Cancer and the American Joint Committee on Cancer. Cancer. 1997;80(9):1803-4.

24. Cox JD, Stetz J, Pajak TF. Toxicity criteria of the Radiation Therapy Oncology Group (RTOG) and the European Organization for Research and Treatment of Cancer (EORTC). Int J Radiat Oncol Biol Phys. 1995;31 (5):1341-6.

25. Roach 3rd M, Hanks G, Thames Jr H, Schellhammer P, Shipley WU, Sokol GH, et al. Defining biochemical failure following radiotherapy with or without hormonal therapy in men with clinically localized prostate cancer: recommendations of the RTOG-ASTRO Phoenix Consensus Conference. Int J Radiat Oncol Biol Phys. 2006;65(4):965-74.

26. Zelefsky MJ, Fuks Z, Hunt M, Lee HJ, Lombardi D, Ling CC, et al. High dose radiation delivered by intensity modulated conformal radiotherapy improves the outcome of localized prostate cancer. J Urol. 2001;166(3):876-81.

27. Kaplan $E$, Meier P. Nonparametric estimation from incompete observations. J Am Stat Assoc. 1958:53:457-81.

28. Kotte AN, Hofman P, Lagendijk JJ, van Vulpen M, van der Heide UA. Intrafraction motion of the prostate during external-beam radiation therapy: 
analysis of 427 patients with implanted fiducial markers. Int J Radiat Oncol Biol Phys. 2007;69(2):419-25.

29. Middleton M, See A, Rolfo A, Medwell S, Joon ML, Joon DL, et al. Intraprostatic fiducials for image guidance: Workflow implications in a single linac department. Radiography. 2008;14(4):312-7.

30. Oehler C, Lang S, Dimmerling P, Bolesch C, Kloeck S, Tini A, et al. PTV margin definition in hypofractionated IGRT of localized prostate cancer using cone beam $\mathrm{CT}$ and orthogonal image pairs with fiducial markers. Radiat Oncol. 2014;9(1):229.

31. Viani GA, da Silva LG, Stefano EJ. High-dose conformal radiotherapy reduces prostate cancer-specific mortality: results of a meta-analysis. Int J Radiat Oncol Biol Phys. 2012;83(5):e619-25.

32. Arcangeli G, Fowler J, Gomellini S, Arcangeli S, Saracino B, Petrongari MG et al. Acute and late toxicity in a randomized trial of conventional versus hypofractionated three-dimensional conformal radiotherapy for prostate cancer. Int J Radiat Oncol Biol Phys. 2011;79(4):1013-21.

33. Dearnaley D, Syndikus I, Sumo G, Bidmead M, Bloomfield D, Clark C, et al. Conventional versus hypofractionated high-dose intensity-modulated radiotherapy for prostate cancer: preliminary safety results from the CHHiP randomised controlled trial. Lancet Oncol. 2012;13(1):43-54.

34. Kuban DA, Nogueras-Gonzalez GM, Hamblin L, Lee AK, Choi S, Frank SJ, et al. Preliminary report of a randomized dose escalation trial for prostate cancer using hypofractionation. Int J Radiat Oncol Biol Phys. 2010;78(3):S58-9.

35. Pollack A, Hanlon AL, Horwitz EM, Feigenberg SJ, Konski AA, Movsas B, et al. Dosimetry and preliminary acute toxicity in the first 100 men treated for prostate cancer on a randomized hypofractionation dose escalation trial. Int J Radiat Oncol Biol Phys. 2006;64(2):518-26.

36. Pollack A, Walker G, Buyyounouski M, Horwitz E, Price R, Feigenberg S, et al. Five year results of a randomized external beam radiotherapy hypofractionation trial for prostate cancer. Int J Radiat Oncol Biol Phys. 2011;81(2):S1.

37. Arcangeli S, Strigari L, Gomellini S, Saracino B, Petrongari MG, Pinnaro P, et al. Updated results and patterns of failure in a randomized hypofractionation trial for high-risk prostate cancer. Int J Radiat Oncol Biol Phys. 2012;84(5):1172-8.

38. Arcangeli G, Saracino B, Gomellini S, Petrongari MG, Arcangeli S, Sentinelli S, et al. A prospective phase III randomized trial of hypofractionation versus conventional fractionation in patients with high-risk prostate cancer. Int J Radiat Oncol Biol Phys. 2010;78(1):11-8.

39. Hegemann NS, Guckenberger M, Belka C, Ganswindt U, Manapov F, Li M. Hypofractionated radiotherapy for prostate cancer. Radiat Oncol. 2014;9(1):275

40. Taira AV, Merrick GS, Galbreath RW, Butler WM, Lief J, Adamovich E, et al. Distant metastases following permanent interstitial brachytherapy for patients with clinically localized prostate cancer. Int J Radiat Oncol Biol Phys. 2012;82(2):e225-32.

41. Ghadjar P, Oesch SL, Rentsch CA, Isaak B, Cihoric N, Manser P, et al. Late toxicity and five year outcomes after high-dose-rate brachytherapy as a monotherapy for localized prostate cancer. Radiat Oncol. 2014;9:122.

42. King CR, Brooks JD, Gill H, Presti Jr JC. Long-term outcomes from a prospective trial of stereotactic body radiotherapy for low-risk prostate cancer. Int J Radiat Oncol Biol Phys. 2012;82(2):877-82.

43. Loblaw A, Cheung P, D'Alimonte L, Deabreu A, Mamedov A, Zhang L, et al. Prostate stereotactic ablative body radiotherapy using a standard linear accelerator: Toxicity, biochemical, and pathological outcomes. Radiother Oncol. 2013;107(2):153-8.

44. Madsen BL, Hsi RA, Pham HT, Fowler JF, Esagui L, Corman J. Stereotactic hypofractionated accurate radiotherapy of the prostate (SHARP), 33.5 Gy in five fractions for localized disease: first clinical trial results. Int J Radiat Oncol Biol Phys. 2007;67(4):1099-105.

45. Ritter M, Forman J, Kupelian P, Lawton C, Petereit D. Hypofractionation for prostate cancer. Cancer J. 2009;15(1):1-6.

46. Tang Cl, Loblaw DA, Cheung P, Holden L, Morton G, Basran PS, et al. Phase I/I study of a five-fraction hypofractionated accelerated radiotherapy treatment for low-risk localised prostate cancer: early results of pHART3. Clin Oncol (R Coll Radiol). 2008;20(10):729-37.

47. Meier R, Cotrutz C, Loiselle C, Sima S, Vermeulen S. Long-term outcomes of stereotactic body radiation therapy for organ-confined prostate cancer. Int J Radiat Oncol Biol Phys. 2012;84(3):S417.

\section{Submit your next manuscript to BioMed Central and take full advantage of:}

- Convenient online submission

- Thorough peer review

- No space constraints or color figure charges

- Immediate publication on acceptance

- Inclusion in PubMed, CAS, Scopus and Google Scholar

- Research which is freely available for redistribution

Submit your manuscript at www.biomedcentral.com/submit 